because of disordered function of the temporal lobe, which may be related to disorder of structure when morphological study is available. It follows that even though the lesion may be a small one the patient is brain-damaged, to use a topical phrase. As the part of the brain damaged is responsible for the integration of all sensation into total experience, and as that experience is primarily responsible for behaviour, it would not be surprising if the epilepsy was associated with psychological disorders reflected in disturbance of mood or attitude, or evident in disturbed social behaviour. That of course is the case, for so many people with aggressive psychopathic behaviour also have disturbance of this part of the brain either reflected in the electroencephalogram or in morbid anatomical studies.

If the clinician will keep clearly before him the distinction between what happens in the attack itself (the ictus) and what results from the post-ictal confusional state, and will then divorce these events from the total behaviour of the patient, he will be doing just what the neurologist does when he is faced with the much simpler situation in a patient who has a parietal lobe lesion. In this case there may be a hemiplegia with disturbance of fecling which will affect the patient's behaviour at a lower level of functional integration, and this disturbance of movement or behaviour may well be associated with attacks of a parietal lobe kind-that is to say, a focal fit affecting arm or leg. In this simple situation there is no difficulty in distinguishing between the intermittent epileptic event and the continued life handicap. Although the distinction is much less obvious with temporal lobe lesions, it exists, and in practice it can in most cases be made. To know that it exists will prevent serious mistakes. Lastly, a point which has been made before must be re-emphasized-that in any epileptic patient the impact of the attacks upon the subject's life is apt to lead to psycho- logical difficulties the effects of which are to increase the frequency of attacks and severity of epilepsy ; when the epilepsy includes in its experiences psychic disturbances it is particularly prone to be aggravated by psychological distress.

\section{Summary}

Although elaborate experiences and acts characterize temporal lobe epilepsy, they simply reflect a focal fit which can be related to the cortex involved, as in the more simple focal epilepsies.

The lobe serves perception; it integrates those feelings arising within the person, including the emotions and moods, as well as percepts from the outside world, to achieve the sense of being.

Subjects of temporal lobe epilepsy may consequently experience sensory illusions or hallucinations or disturbances of emotion or mood. They may also experience disintegration of the self with feelings of depersonalization or derealization which result from disturbances of the integrative function of the lobe.

Since the awareness of time is essential to perceptual integration, the attacks may also include temporal illusions.

The movements seen in the attacks are always co-ordinated, so that they may seem to be purposeful, although it is the observer who ascribes purpose to them. If complex activity is in fact directed towards a goal it is most unlikely to be due to temporal epilepsy.

Patients with damage to the temporal lobe often have disorders of feeling and behaviour due to its ${ }^{*}$ disordered function, which must be clearly distinguished from the effects of epilepsy arising in it.

\title{
Local Complications of Ulcerative Colitis: Stricture, Pseudopolyposis, and Carcinoma of Colon and Rectum*
}

\author{
F. T. DE DOMBAL, † M.B., B.CHIR.; J. MCK. WATTS, $\ddagger$ M.B., F.R.A.C.S. ; G. WATKINSON,§ M.D., F.R.C.P. \\ J. C. GOLIGHER, $\|$ CH.M., F.R.C.S.
}

Brit. med. F., 1966, 1, 1442-1447

Part of the notoriety which ulcerative colitis enjoys is derived from the diversity of complications accompanying this disease. We have reported elsewhere on the rectal and perirectal complications of colitis (de Dombal, Watts, Watkinson, and Goligher, 1966) and on perforation of the colon (de Dombal, Watts, Watkinson, and Goligher, 1965). In this paper we propose to consider three further important local complications ; these are stricture, pseudopolyposis, and carcinoma of the colon and rectum.

\section{Clinical Material and Methods}

The complications reported in this paper were recorded during a survey of 465 patients with ulcerative colitis, including every patient who attended the colitis clinic in Leeds during the period 1952-63. This is a retrospective study based on case records, operative notes, and pathological data recorded at the time, and on interview with 416 of the 424 patients who were still alive at the end of 1963 . The eight remaining surviving patients answered a detailed postal questionnaire.

Attacks of colitis were classed as mild, moderate, or severe, according to the criteria of Truelove and Witts (1955). The extent of colitis was repeatedly estimated by means of barium enema and by sigmoidoscopy. Both the severity and extent of disease were reassessed each year on the basis of information available in that year.

In our follow-up studies we have made use of the concept of a "patient-yvar" under observation-that is, one complete year of follow-up of an individual patient. This concept has been used by Dennis and Karlson (1961), MacDougall (1964), and also by ourselves in a study of the long-term prognosis of ulcerative colitis (Watts, de Dombal, Watkinson, and Goligher, 1966).

* From the Colitis Clinic, the General Infirmary, Leeds.

† Research Assistant, Professorial Surgical Unit, the General Infirmary at Leeds.

‡Formerly Edward Lumley Research Fellow of the Royal Australasian College of Surgeons, and Licturer in Surgery, Professorial Surgical Unit the General Infirmary at Leeds. Present address: Department Unit, the General Infirmary at Leeds. Alfred Hospital, Melbourne, Australia.

Consultant Physician to the York Hospitals.

If Professor of Surgery, the General Infirmary at Leeds.

Address for reprints: Professor J. C. Goligher, Department of Surgery, the General Infirmary, Leeds. 
During the survey of 465 patients $96(20.6 \%)$ were found to have one or more of these three complications. Table I shows the incidence of each of these complications in the 465 patients surveyed. Our experience of each individual complication is dealt with in detail.

TABLE I.-Incidence of Individual Local Complications Among 465 Patients

\begin{tabular}{|c|c|c|c|c|c|c|c|c|}
\hline \multicolumn{8}{|c|}{ Complications } & \multirow{2}{*}{$\begin{array}{c}\text { No. of Patients } \\
52(11.2 \%) \\
58(12.5 \%) \\
8(1.7 \%)\end{array}$} \\
\hline $\begin{array}{l}\text { Stricture .. } \\
\text { Pseudopolyposis } \\
\text { Carcinoma .. }\end{array}$ & $\begin{array}{l}\cdots \\
\cdots \\
\end{array}$ & $\begin{array}{l}\cdots \\
\cdots \\
\end{array}$ & $\begin{array}{l}\cdots \\
\cdots \\
\end{array}$ & $\begin{array}{l}\cdots \\
\cdots \\
\end{array}$ & $\begin{array}{l}\cdots \\
\cdots \\
\cdots\end{array}$ & $\begin{array}{l}\cdots \\
\cdots \\
\cdots\end{array}$ & $\begin{array}{l}\cdots \\
\cdots \\
\end{array}$ & \\
\hline One or more & . & . & . & . & . & . & . & $96(20 \cdot 6 \%)$ \\
\hline
\end{tabular}

\section{Stricture of the Colon or Rectum}

Incidence.-For the purpose of this analysis stricture is defined as a constant narrowing the lumen of the colon or rectum. This complication was found in 52 patients, $11.2 \%$ of those surveyed. Ten of these patients were found to have multiple strictures, so that the total number of strictures detected was 67. Fifty of these strictures were detected clinically by rectal examination or by barium enema; the remainder were unsuspected clinically, and were found only upon examination of the bowel after excision.

Anatomical Site of Stricture.-The site of each of the 67 strictures of the colon and rectum is shown in Table II. It also shows the frequency with which each area of the bowel was involved by colitis. Of the 428 patients with involvement of the rectum $7.9 \%$ developed rectal stricture. Though the ascending colon was involved by colitis in only 140 patients, $7(5 \%)$ of these developed stricture at this site. TABLE II.-Incidence of Stricture at Varying Sites in the Colon and
Rectum

\begin{tabular}{|c|c|c|c|c|}
\hline Site & & & $\begin{array}{l}\text { No. of Patients } \\
\text { with Involvement } \\
\text { by Colitis }\end{array}$ & No. of Strictures \\
\hline $\begin{array}{l}\text { Rectum } \quad \ldots \\
\text { Sigmoid } \quad \ldots \\
\text { Descending colon } \\
\text { Transverse colon } \\
\text { Ascending colon }\end{array}$ & $\begin{array}{l}\ldots \\
\cdots \\
\ldots\end{array}$ & $\begin{array}{l}\ldots \\
\because \\
\cdots\end{array}$ & $\begin{array}{l}428 \\
344 \\
280 \\
210 \\
140\end{array}$ & $\begin{aligned} & 34(7.9 \%) \\
& 8(2.3 \%) \\
& 7(2.5 \%) \\
& 11(5.2 \%) \\
& 7(5.0 \%)\end{aligned}$ \\
\hline
\end{tabular}

Extent of Colitis.-Stricture formation was most common when the whole colon was diseased. Table III shows the maximum extent of disease recorded in 428 patients surveyed, and the incidence of stricture in each group of patients. Stricture developed in the rectum in only 3 out of 84 patients with proctitis; but of patients with total involvement of the colon and rectum more than $17 \%$ developed a stricture.

TABLE III.-Influence of the Extent of Colitis upon the Incidence of Stricture

\begin{tabular}{|c|c|c|c|c|c|}
\hline Extent & & & & $\begin{array}{l}\text { No. of } \\
\text { Patients }\end{array}$ & $\begin{array}{l}\text { No. with } \\
\text { Stricture }\end{array}$ \\
\hline $\begin{array}{l}\text { Rectum } \\
\text { Rectum and left colon } \\
\text { Rectum and left and right colon }\end{array}$ & $\because$ & $\begin{array}{l}\cdots \\
\cdots\end{array}$ & $\begin{array}{l}\cdots \\
\cdots\end{array}$ & $\begin{array}{r}84 \\
134 \\
210\end{array}$ & $\begin{array}{r}3(3.6 \%) \\
10(7.5 \%) \\
36(17.1 \%)\end{array}$ \\
\hline
\end{tabular}

Excludes 37 patients with other or unknown extent of colitis. Difference between left-sided colonic involvement and total colonic involvement is significant $\left(\chi^{2}=6.61\right.$;
$\mathrm{n}=1 ; P<0.01)$.

Duration of Colitic Symptoms.-Six of 41 patients seen in a severe initial attack of colitis were found to have a stricture (Table IV). In four of these the stricture was discovered on clinical examination, but in the other two it was unsuspected prior to operation. Only 23 patients came to surgery during their first attack of colitis, and stricture was found in the colon or rectum of six of these patients on routine post-operative histological examination. A further analysis of patient-years shows that the incidence of detection of strictures in each patient-year was remarkably little affected by the duration of colitic symptoms.

TABLE IV.-Incidence of Stricture Related to the Duration of Colitic Symptoms at Time of Stricture Detection

\begin{tabular}{|c|c|c|c|c|c|c|}
\hline \multicolumn{4}{|c|}{ Duration of Symptoms } & \multirow{2}{*}{$\begin{array}{c}\begin{array}{c}\text { No. of } \\
\text { Patient-years }\end{array} \\
204 \\
1,027 \\
211 \\
138\end{array}$} & \multirow{2}{*}{$\begin{array}{c}\begin{array}{c}\text { No. of } \\
\text { Strictures } \\
\text { Detected }\end{array} \\
6 \\
31 \\
10 \\
4\end{array}$} & \multirow{2}{*}{$\begin{array}{c}\begin{array}{c}\text { Incidence } \\
\text { per }\end{array} \\
\text { Patient-year }\end{array}$} \\
\hline $\begin{array}{c}0-1 \text { year } \\
1-9 \text { years } \quad \ldots \\
10-19 \text { ". } \\
20 \text { years and over }\end{array}$ & $\begin{array}{l}\ldots \\
\ldots\end{array}$ & $\begin{array}{l}\ldots \\
\cdots \\
\cdots\end{array}$ & $\begin{array}{l}\ldots \\
\cdots \\
\ldots\end{array}$ & & & \\
\hline
\end{tabular}

Excludes one stricture the time of detection of which was unknown.

Relationship to Carcinoma.-Despite the fact that 35 out of 52 patients with stricture came to surgery, carcinoma of the colon or rectum was discovered in only one of these patients. Furthermore, this carcinoma was not at the site of the stricture ; it occurred in the sigmoid colon of a patient with a pre-existing fibrous rectal stricture.

Pathological Features.-In 56 instances the stricture was localized, and the narrowing of the lumen of the bowel was restricted to 2 or $3 \mathrm{~cm}$. in length. The remaining 11 strictures were diffuse, and in these the lumen of the bowel was narrowed for a distance of up to $30 \mathrm{~cm}$. Precise histological details were available for 28 strictures. The predominating feature in most of these was marked submucosal fibrosis, which was found in 20. Mucosal hyperplasia was seen' in five strictures, and musculature hypertrophy in the remaining three.

\section{Discussion}

The incidence of stricture in our 465 patients is higher than the incidence noted in most other large surveys of ulcerative colitis (Bargen, 1930 ; Sloan, Bargen, and Baggenstoss, 1950 ; Jackman, 1954 ; Edwards and Truelove, 1964). This may be attributed to the inclusion in our total figures of all strictures which were found on routine post-operative pathological examination, some of which were not detected clinically. Conversely, however, in every patient who came to surgery with a pre-operative diagnosis of stricture, this stricture was demonstrated on post-operative examination of the excised colon and rectum.

Stricture of the colon is generally held to be a manifestation of chronic disease. However, one-quarter of the patients who came to surgery during their first attack of colitis were found to have a stricture at that time, and in two of these six patients the stricture was unsuspected clinically. It thus appears that stricture formation may not infrequently begin during a severe initial attack of colitis, though such a stricture may not become clinically apparent until some years later.

Our survey confirms that the rectum is the commonest site of stricture formation. However, Table II also shows that this preponderance of rectal stricture is due, in part, to the fact that the rectum was more often involved by colitis than any other area of the colon. When this factor is taken into consideration there is no significant difference between the incidence of strictures in the rectum and the incidence in other areas of the large bowel.

Brooke (1961) points out that the carcinoma may occur at the site of a stricture ; indeed, Edwards and Truelove (1964) believe fibrous stricture to be an indication for surgery, owing to the possibility of malignant degeneration. It is therefore worth recording that we have failed to discover a single instance of carcinoma developing at the site of a stricture of the rectum or colon, despite post-operative histological examination of the stricture in all but 17 of the 52 patients.

We believe that this failure to find carcinoma is due to the short duration of colitis in many of our patients with stricture ; and our data suggest that a stricture which develops within 10 
years of the onset of colitic symptoms is likely to be fibrous in nature and not malignant.

\section{Pseudopolyposis}

Incidence.-We have included for the purpose of this analysis all three types of inflammatory pseudopolyp described by Dukes (1954). These are: (1) polypoid oedematous mucosal tags, (2) polyps composed of granulation tissue covered by mucous membrane, and (3) polyps composed of connective tissue covered by a layer of glandular epithelium. When so defined, pseudopolyps occurred in 58 of our 465 patients with ulcerative colitis, an incidence of $12.5 \%$. Of the 204 patients seen during an initial attack of colitis $18(8.8 \%)$ were found to have pseudopolyps at that time: while of 41 patients first seen in a severe initial attack of colitis $12(29.3 \%)$ were found at that time to have pseudopolyposis.

Extent and Severity of Colitis.-No patient whose disease was restricted to the rectum developed pseudopolyposis, but nearly $20 \%$ of patients with total or subtotal involvement of the colon were found to have pseudopolyps (Table V). Pseudopolyposis is generally assumed to be a manifestation of severe disease, and in 22 of our 58 patients with pseudopolyps the latter were discovered during the course of a severe attack of colitis (though they may have been present for some time).

TABLE V.-Incidence of Pseudopolyposis with Varying Extent of Colitis

\begin{tabular}{|c|c|c|c|}
\hline Extent & & $\begin{array}{l}\text { No. of } \\
\text { Patients }\end{array}$ & $\begin{array}{l}\text { No. with } \\
\text { Pseudopolyps }\end{array}$ \\
\hline $\begin{array}{l}\text { Rectum alone } \\
\Rightarrow \quad \text { and left-side colon } . \\
\text { and left- and right-side colon }\end{array}$ & $\begin{array}{ll}. . & \cdots \\
\cdots & \cdots\end{array}$ & $\begin{array}{r}84 \\
134 \\
210\end{array}$ & $\begin{array}{l}0 \\
13(9 \cdot 7 \%) \\
41(19.5 \%)\end{array}$ \\
\hline
\end{tabular}

Difference between the left-sided colonic involvement and total colonic is significant $\left(x^{2}=5.96 ; n=1 ; P<0.02\right)$.

Extent of Pseudopolyposis.-In 25 patients estimation of the extent of pseudopolyposis was possible by direct examination of the excised colon and rectum. The extent of pseudopolyposis in these patients is shown in Table VI. Other patients who did not come to surgery, or whose pathological reports do not state the extent of pseudopolyposis, have been excluded from this table. Pseudopolyps were most commonly found in the transverse and the descending colon. The least common site was the rectum, and in patients so affected the pseudopolyposis was usually restricted to the upper third of the rectum.

TABLE VI.-Areas Involved by Pseudopolyposis in 25 Proctocolectomy Specimens

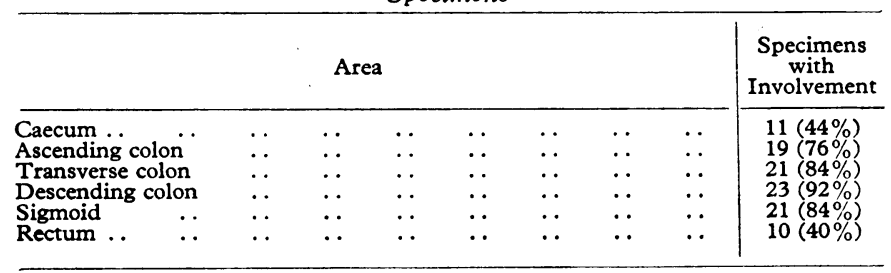

Relation to Carcinoma.-Two of the 48 patients with pseudopolyps also developed frank invasive carcinoma of the colon or rectum; but this incidence $(3.4 \%)$ is not greatly higher than the incidence of carcinoma (1.5\%) in the remaining patients surveyed. Both of these patients had total involvement of the colon: their duration of colitic symptoms was 12 and 30 years respectively. One other patient with pseudopolyposis was also found to have true adenomatous polyps; this patient was reported as having developed carcinoma-in-situ in one of these true adenomatous polyps.

\section{Discussion}

Pseudopolyposis is probably the most common local complication in ulcerative colitis, being present in $12.5 \%$ of our patients. A similar high incidence of pseudopolyposis has been found in other surveys (Sloan et al., 1950 ; Brown, Kasich, and Weingarten, 1951 ; Van Prohaska and Siderius, 1962).

It has been claimed that pseudopolyposis occurs most commonly in the rectum (Sloan et al., 1950) and in the left side of the colon (Edwards and Truelove, 1964). Our findings on clinical examination, including assessment by sigmoidoscopy and barium enema, agreed with this opinion. However, in 25 instances direct inspection was possible of the excised colon and rectum after proctocolectomy. The extent of pseudopolyposis in these patients was much greater than we had previously supposed after clinical and radiological examination. In most of these patients involvement began proximally in the ascending colon, and extended distally as far as the rectosigmoid junction. In the few patients with rectal pseudopolyposis this complication was rare within $10 \mathrm{~cm}$. of the anal verge.

Is pseudopolyposis a pre-cancerous change ? Bacon, Yang, Carroll, Cates, Villalba, and McGregor (1956) suggest that it is so, for they list 48 cases with pseudopolyposis, of which nine developed carcinoma; moreover, Dawson and Pryse-Davies (1959) claim to show examples of a transitional stage between pseudopolyps and adenomatous polyps.

However, we believe that this is due to the extent and severity of the disease rather than to any specific pre-cancerous change. Only one of our 58 patients with pseudopolyposis was found to have true adenomatous polyps, and it is noteworthy that both the patients in this group who developed carcinoma suffered from long-standing extensive colitis.

\section{Carcinoma of the Colon and Rectum}

Incidence.-Recent studies have shown that atypical epithelium in adenomatous polyps may be too readily interpreted as carcinoma (Castleman and Krickstein, 1962). We have therefore decided to restrict the present analysis to patients with frank invasive carcinoma. Eight of our patients, $1.7 \%$ of those surveyed, developed frank invasive carcinoma of the colon or rectum during their period of medical follow-up.

We have excluded from the present study a further four patients reported to have carcinoma-in-situ on routine histological examination after proctocolectomy. These include three patients reported as having carcinoma-in-situ in true adenomatous polyps. Another patient with colitis and carcinoma, who was referred here specifically for surgery, has also been excluded from the present analysis.

Site.-Seven carcinomata were situated in the rectum and sigmoid (Table VII); the remaining carcinoma was found just proximal to the hepatic flexure. Table VII also shows the total number of patients with involvement of each area by coliti. When this factor is taken into account, though the incidence of carcinoma is greater in the rectum than elsewhere, nowhere is this difference significant.

TABLE VII.-Incidence of Carcinoma in Colon and Rectum, Compared with Frequency of Involvement of Each Area by Colitis

\begin{tabular}{|c|c|c|c|c|c|c|}
\hline \multicolumn{5}{|c|}{ Anatomical Site } & \multirow{2}{*}{$\begin{array}{c}\begin{array}{c}\text { Patients with } \\
\text { Involvement } \\
\text { by Colitis }\end{array} \\
428 \\
344 \\
280 \\
210 \\
140\end{array}$} & \multirow{2}{*}{$\begin{array}{l}\begin{array}{c}\text { No. of } \\
\text { Carcinomas }\end{array} \\
4(0.9 \%) \\
3(0.9 \%) \\
0 \\
0 \\
1(0.7 \%)\end{array}$} \\
\hline $\begin{array}{l}\text { Rectum } \ldots \\
\text { Sigmoid colon } . \\
\text { Descending colon } \\
\text { Transverse colon } \\
\text { Ascending colon }\end{array}$ & $\begin{array}{l}\ldots \\
\cdots \\
\cdots\end{array}$ & $\begin{array}{l}\ldots \\
\because \\
\therefore\end{array}$ & $\begin{array}{l}\ldots \\
\cdots \\
\cdots\end{array}$ & $\begin{array}{l}\ldots \\
\cdots \\
\cdots\end{array}$ & & \\
\hline
\end{tabular}

Extent of Colitis.-The maximum extent of colitis recorded in each of 428 of the patients surveyed is shown in Table VIII. Patients with unknown extent of colitis (one of whom developed carcinoma) or with right-sided or segmental colitis are excluded. Table VIII also shows that carcinoma of the colon and rectum in our 465 patients occurs almost entirely in those patients with 
total or subtotal colonic involvement. None of the 218 patients with disease limited to the rectum or to the left side of the colon developed carcinoma.

TABLE VIII.-Influence of Extent of Colitis on the Incidence of
Carcinoma of Colon or Rectum

Duration of Colitis.-The date of onset of colitic symptoms was noted for all but one of the 465 patients surveyed, and thus the duration of their colitic symptoms during the patientyears under observation was known. Table IX shows that the incidence of carcinoma in our whole group of patients per patient-year under observation rises with the duration of colitic symptoms; and Fig. 1 shows the cumulative incidence of carcinoma in our whole group of 465 patients (calculated by actuarial method from the data in Table IX). The cumulative incidence is shown to rise to $25.8 \%$ after 25 years of colitic symptoms. However, the incidence in our whole group of patients is somewhat misleading, for it has been shown that,

TABLE IX.-Incidence of Carcinoma of Colon or Rectum per Patientyear, in 465 Patients with Ulcerative Colitis, According to Duration of Colitis Symptoms

\begin{tabular}{|c|c|c|c|c|c|c|}
\hline \multicolumn{4}{|c|}{ Duration of Symptoms } & $\begin{array}{c}\text { Observed } \\
\text { Patient-rears }\end{array}$ & No. of & $\begin{array}{l}\text { Incidence of } \\
\text { Carcinoma per }\end{array}$ \\
\hline $\begin{array}{ccc}1-9 & \text { years } & \\
10-19 & \Rightarrow & \cdots \\
20+ & \# & \cdots\end{array}$ & $\because \ddot{ }$ & $\ddot{a}$ & $\ddot{\prime}$ & $\begin{array}{r}1,027 \\
211 \\
138\end{array}$ & $\begin{array}{l}1 \\
3 \\
4\end{array}$ & $\begin{array}{l}0.1 \% \\
1.4 \% \\
2.9 \%\end{array}$ \\
\hline
\end{tabular}
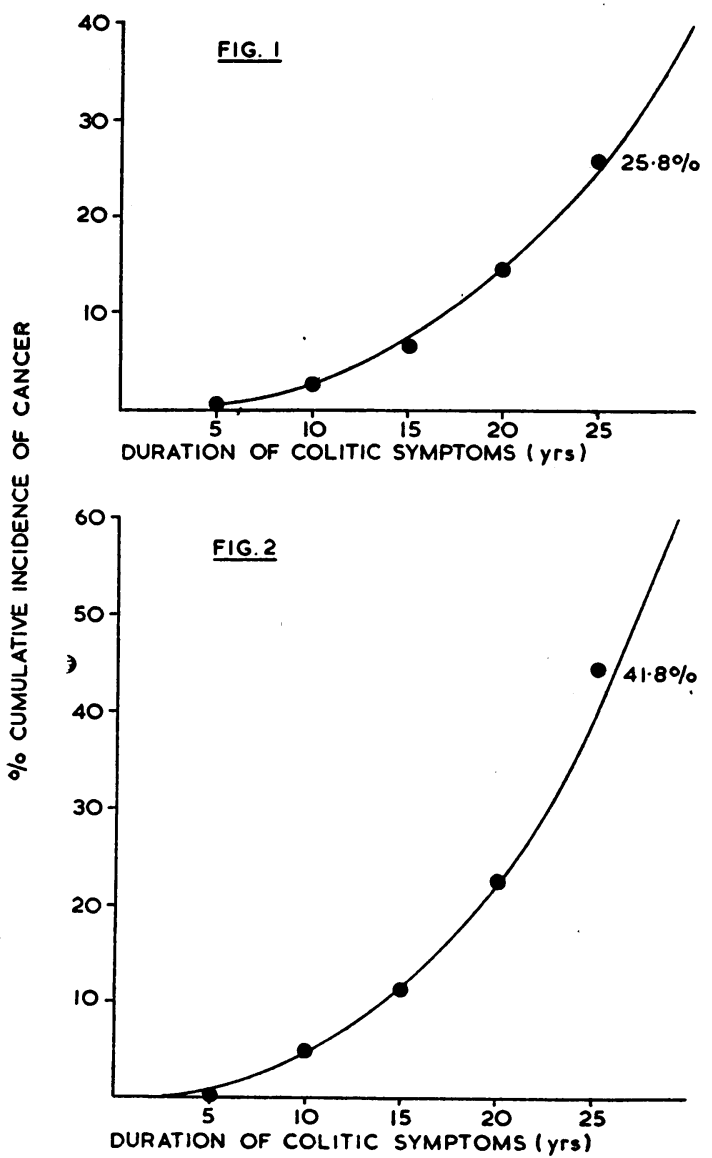

Fig. 1.-Cumulative expected incidence of carcinoma with ulcerative colitis, up to 25 years after the onset of symptoms, based on data from 465 patients. FIG. 2.Cumulative expected incidence of carcinoma in patients with total involvement, up to 25 years after the onset of symptoms, based on data from 210 patients. in our patients, carcinoma occurs almost exclusively in those with total or subtotal involvement of the colon. Table $\mathrm{X}$ shows the more pronounced yearly risk in these patients with extensive colitis, being $5.8 \%$ in each year after 20 years of colitic symptoms ; and Fig. 2 shows the cumulative expected incidence of carcinoma in these patients to be no less than $41.8 \%$ after 25 years of colitic symptoms.

TABLE X.-Incidence of Carcinoma per Patient-year According to Duration of Colitic Symptoms, in 210 Patients with. Involvement of Rectum and Both Sides of Colon by Colitis

\begin{tabular}{|c|c|c|c|c|c|c|c|}
\hline \multicolumn{5}{|c|}{ Duration of Symptoms } & \multirow{2}{*}{$\begin{array}{c}\begin{array}{c}\text { Observed } \\
\text { Patient-years }\end{array} \\
282 \\
101 \\
69\end{array}$} & \multirow{2}{*}{ 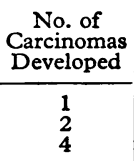 } & \multirow{2}{*}{\begin{tabular}{|c} 
Incidence of \\
Carcinoma per \\
Patient-year
\end{tabular}} \\
\hline 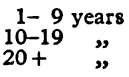 & $\begin{array}{l}\cdots \\
\therefore\end{array}$ & $\begin{array}{l}\ldots \\
\cdots\end{array}$ & $\begin{array}{l}\cdots \\
\therefore\end{array}$ & $\begin{array}{l}. \\
\therefore\end{array}$ & & & \\
\hline
\end{tabular}

Pathological Details.-The well-recorded difficulties in diagnosis were emphasized by a study of the six growths removed surgically. On macroscopic examination four of the six were described as being ill-defined areas of induration, or ulceration of papillomata. The remaining two growths were well-defined malignant ulcers.

Microscopical details were available for seven of the growths, as one of the patients who did not come to surgery had a rectal biopsy. All were adenocarcinomata, three being well differentiated and four poorly differentiated. In only two of the seven growths was secretion of mucus noted; and pronounced fibrous reaction was not observed in any of our patients.

Treatment and Outcome.-Seven patients were treated surgically: five by total proctocolectomy, one by rectal excision, and one by laparotomy and closure. The remaining patient died before surgery could be undertaken. There were five deaths in this group of eight patients ; apart from the patient who died without coming to operation, two patients died in the early post-operative period and there were two late deaths. All were related to carcinoma. Three patients were still alive after one, one, and three years; at review all were in good or excellent general health, but in one patient resection of the carcinoma was purely palliative.

\section{Discussion}

Carcinoma of the large bowel in a patient with ulcerative colitis was reported by Crohn and Rosenberg in 1925, and by 1928 a series of such cases attending the Mayo Clinic had been collected by Bargen (1928). Since then many workers have investigated the relationship between the two conditions (Svartz and Ernberg, 1949 ; Counsell and Dukes, 1952 ; Goldgraber, Humphreys, Kirsner, and Palmer, 1958 ; Dawson and PryseDavies, 1959 ; Slaney and Brooke, 1959 ; Bargen and Gage, 1960 ; Brooke, 1961 ; Dennis and Karlson, 1961 ; Russell and Hughes, 1961 ; Nefzger and Acheson, 1963 ; Edwards and Truelove, 1964 ; MacDougall, 1964). As a result of these and other surveys, it is now widely accepted that there is an increased risk of carcinoma of the colon and rectum in patients with ulcerative colitis.

In our group of 465 patients with ulcerative colitis eight have developed invasive carcinoma of the colon or rectum, from which five of these patients have died. We cannot compare the incidence of carcinoma in our patients with that in the general population, for the incidence in the latter is difficult to assess. We have, however, compared the observed fatality rate due to carcinoma of the colon and rectum in our colitic patients $(2.68$ deaths per 1,000 patients per annum) with the expected fatality rate due to carcinoma of the colon and rectum in a sample of the general population matched for age and sex $(0.24$ deaths per 1,000 patients per annum) (Register-General, 1962). 
The observed fatality rate due to carcinoma in our group was therefore 11 times the expected death rate due to carcinoma in a sample of the general population matched for age and sex.

It is widely held that the incidence of carcinoma depends upon the duration of colitic symptoms. Table IX confirms that a similar trend exists in our patients. We have used these data to calculate the cumulative incidence of carcinoma at intervals of five years up to 25 years from the onset of colitic symptoms (Fig. 1). We have been able to include all but one of our patients because we have interviewed all except eight of the surviving patients; and our estimate of the date of onset of symptoms has been derived from a study of the patient's history made in the presence of the patient and supplemented by the patient's own recollections.

It must be emphasized that after 20 years' duration of symptoms our total numbers are small. However, there is no doubt that in this small group of patients the incidence of carcinoma is very high, and Fig. 1 suggests that the cumulative incidence of carcinoma in our 465 subjects may after 25 years be as high as $26 \%$.

Previous studies have further shown that the risk of carcinoma varies with the extent of colitis; and the incidence of carcinoma in those of our patients whose colitis is restricted to the left side of the colon and to the rectum is nil, even after 30 years of colitic symptoms. However, among those of our patients with involvement of both sides of the colon and the rectum, while the cumulative risk of carcinoma is $13 \%$ after 15 years, the cumulative risk rises to no less than $41.8 \%$ after 25 years. It can also be seen from Table $\mathrm{X}$ that any patient with total involvement of the colon and rectum, first seen 20 or more years after the onset of colitis, has a risk of developing carcinoma of at least $5 \%$ each year for the rest of his life. We have seen 26 patients to whom these criteria apply, and, of these 26 , three are already dead as a result of carcinoma, and we have been able to offer only palliation to a fourth with this complication.

\section{Prophylactic Proctocolectomy}

These disquieting figures must naturally raise the question of prophylactic proctocolectomy. Opinion on the advisability of this step is divided. Texter (1957) states that the frequency of malignant degeneration is insufficient to warrant total colectomy for this reason alone. By contrast, Dennis and Karlson (1961) advocate removal of any colon which is still radiologically abnormal four years after the onset of colitis.

Michener, Gage, Sauer, and Stickler (1961) followed up 401 children with ulcerative colitis, and found that carcinoma developed in $46(11.5 \%)$, thus confirming the earlier findings of Rosenqvist, Öhrling, Lagercrantz, and Edling (1959) that children with colitis are especially predisposed to develop cancer. However, they make no definitive statement about preventive proctocolectomy.

Nefzger and Acheson (1963) discuss the question at some length. They find preventive colectomy difficult to justify from their figures alone. They quote a high mortality after ileostomy, but several of their cases had simple ileostomy without colectomy and some operations were done urgently. Carleson, Fristedt, and Philipson (1963) are also unable to confirm the view that the risk of cancer justifies an increase of colectomy.

Edwards and Truelove (1964) consider that the risk of carcinoma is outweighed by the other dangers of colitis, but conclude that the risk of elective colectomy is probably substantially less than that of carcinoma developing in certain "high-risk" groups, while MacDougall (1964) recommends prophylactic proctocolectomy to patients with total involvement of the colon and rectum after 10 years of colitic symptoms.

We certainly do not advocate widespread prophylactic colectomy to all patients with long-standing colitis. From our data it appears that this operation, with its attendant operative mortality of about $3 \%$, cannot be justified on the grounds of cancer prevention in patients with distal involvement alone. However, in the group of patients with total or subtotal involvement of the colon who have had colitic symptoms for more than 10 years a very strong case can clearly be argued for this measure. We fully realize that preventive proctocolectomy carries its own dangers and disadvantages for the patient ; but we believe that the risk of cancer in this small group of patients is so high that the drastic step of excisional surgery is fully justified. Furthermore, though the number of cases in our series with symptoms for more than 20 years is small, other longer surveys (Michener et al., 1961 ; Edwards and Truelove, 1964 ; MacDougall, 1964) show trends similar to those revealed in our group of patients.

It has been claimed by Bargen (1961) and Aylett (1964) that careful supervision of patients with colitis will lead to early detection of carcinoma and an improved prognosis. However, this is contrary to our experience ; for, despite the most careful medical supervision of our eight patients who developed carcinoma, the diagnosis was not suspected pre-operatively in three, and five of the eight have died. This gloomy outcome of our patients with established carcinoma tallies only too well with that reported by Dawson and Pryse-Davies (1959), Brooke (1961), and Edwards and Truelove (1964).

On the basis of our data we therefore believe that there is an overwhelming case for removal of the colon and rectum in patients with total involvement by colitis after 10 years of colitic symptoms; because in these patients the dangers and disadvantages of proctocolectomy are outweighed by the very high risk of developing cancer.

\section{Summary}

A survey of 465 patients with ulcerative colitis revealed stricture of the colon or rectum in $52(11.2 \%)$, pseudopolyposis in $58(12.5 \%)$, and frank invasive carcinoma of the colon or rectum in $8(1.7 \%)$.

Strictures were found in one-quarter of the patients who came to surgery during their first attack of colitis. This complication was associated with extensive disease, but, despite histological examination of the majority of cases, no instance of carcinomatous change at the site of a stricture was encountered.

Pseudopolyposis was the most common local complication of colitis. The extent of pseudopolyps in 25 specimens after proctocolectomy was much greater than had been apparent clinically.

The fatality rate due to carcinoma in our 465 patients with colitis was 11 times greater than the expected rate in a matched sample of the general population. The incidence of carcinoma is shown to be related to the duration of colitic symptoms and to the extent of involvement of the colon and rectum by colitis. The cumulative incidence of carcinoma in those patients with total involvement rises after 30 years to $56 \%$.

Prophylactic proctocolectomy is strongly recommended for patients with total involvement of the colon and rectum by colitis who are first seen after 10 years' duration of colitic symptoms, because in these patients the risk of prophylactic proctocolectomy is less than the risk of developing carcinoma.

We would like to express our gratitude to Dr. Richard Doll for his help and advice in the preparation of this paper.

\section{REFERENCES}

Aylett, S. (1964). Lancet, 2, 820 . and McGregor, R. A. (1956). Amer. F. Surg., 92, 688. Bargen, J. A. (1928). Arch. Surg., 17, 561 (1930). Ann. intern. Med., 3, 335. (1961). Dis. Colon Rect., 4, 1. and Gage, R. P (1960). Gastroenterology, 39, 385. 
Brooke, B. N. (1961). Dis. Colon Rect., 4, 393. Brown, M. L., Kasich, A. M., and Weingarten, B. (1951). Amer. F. dig.

Carleson, R., Fristedt, B., and Philipson, J. (1963). Acta chir. scand., $125,486$. Castleman, B., and Krickstein, H. I. (1962). New Engl. F. Med., 267,

Counsell, P. B., and Dukes, C. E. (1952). Brit. F. Surg., 39, 485.

Crohn, B. B., and Rosenberg, H. (1925). Amer. 7. med. Sci., 170, 220 awson, I. M. P., and Pryse-Davies, J. (1959). Brit. f.' Surg., 47, 113

de Dombal, F. T., Watts, J. M., Watkinson, G., and Goligher, J. C. (1966). Awaiting publication.

Dennis, C., and Karlson, K. E Proc. roy. Soc. Med., 58, 713.

Dukes, C. E. (1954). Ann. roy. Coll. Surg. Engl. 14, 389.

Edwards, F. C., and Truelove, S. C. (1964). Gut, 5, 1 .

Goldgraber, M. B., Humphreys, E. M., Kirsner, J. B., and Pálmer, W. L. (1958). Gastroenterology, 34, 809

Jackman, R. J. (1954). Arch. intern. Med., 94, 420.
MacDougall, I. P. M. (1954). Brit. med. F., 1, 852.

Michener, W. M., Gage, R. P., Sauer, W. G., and Stickler, G. B. (1961). New Engl. f. Med., 265, 1075.

Nefzger, M. D., and Acheson, E. D. (1963). Gut, 4, 183.

Registrar-General (1962). Statistical Review of England and Wales, 1962 Part 1, Tables, Medical. H.M.S.O., London.

Rosenqvist, H., Öhrling, H., Lagercrantz, R., and Edling, N. (1959). Lancet, 1, 906.

Russell, I. S., and Hughes, E. S. R. (1961). Aust. N.Z. F. Surg., 30, 306. Slaney, G., and Brooke, B. N. (1959). Lancet, 2, 694.

Sloan, W. P., Bargen, J. A., and Baggenstoss, A. H. (1950). Proc. Mayo Clin., 25, 240,

Svartz, N., and Ernberg, T. (1949). Acta med. scand., 135, 444

Texter, E. C. (1957) Ұ. chron. Dis., 5, 347

Truelove, S. C., and Witts, L. J. (1955). Brit. med. F., 2, 1041.

Van Prohaska, J., and Siderius, N. J. (1962). Surg. Clin. N. Amer., 42, 1245.

Watts, J. McK., de Dombal, F. T., Watkinson, G., and Goligher, J. C. (1966). Brit. med. F., 1, 1447.

\title{
Long-term Prognosis of Ulcerative Colitis*
}

\author{
J. MCK. WATTS, $\dagger$ M.B., F.R.A.C.S. ; F. T. DE DOMBAL, $\ddagger$ M.B., B.CHIR. ; G. WATKINSON,§ M.D., F.R.C.P. \\ J. C. GOLIGHER,\| CH.M., F.R.C.S.
}

Brit. med. F., 1966, 1, 1447-1453

In attempting to define the natural history of any chronic disease considerable difficulties are encountered in the evaluation of follow-up data collected from patients at varying stages in their illness. In idiopathic ulcerative colitis the difficulties are magnified by the irregularly relapsing course usually pursued by this condition.

We have previously described the factors influencing the early course of colitis in 204 "first-attack" patients ; that is to say, patients who present to us in their initial attack of colitis during 1952-63 (Watts, de Dombal, Watkinson, and Goligher, 1966). During this same period another 261 " relapse" patients came under our care. These patients were not seen in their initial attack, but presented to us during relapses of a pre-existing colitis.

In the present paper we analyse the course and outcome of all patients in both groups who have survived, without resort to surgical treatment, their first referred attack (either the initial attack of colitis or a relapse of long-standing disease). Such a method of analysis automatically excludes from this study all patients referred to this clinic specifically for surgical treatment after medical treatment had failed elsewhere.

\section{Clinical Material and Methods}

This paper is based on a survey of 465 patients with idiopathic ulcerative colitis admitted to hospital or referred to a combined medical and surgical colitis clinic under our personal care during 1952-63.

There were 275 females and 190 males, the female:male sex ratio being 1.45. The composition of the series according to sex and age at the onset of symptoms is illustrated in Table I.

\footnotetext{
* From the Colitis Clinic, the General Infirmary at Leeds.
f Formerly Edward Lumley Research Fellow of the Royal Australasian College of Surgeons, and Lecturer in Surgery, Professorial Surgical Unit, the General Infirmary at Leeds. Present address: Department of Surgery, Monash University, Alfred Hospital, Melbourne, Australia.

$¥$ Research Assistant, Professorial Surgical Unit, the General Infirmary at Leeds.

Consultant Physician to the York Hospitals.

II Professor of Surgery, the General Infirmary at Leeds.

Address for reprints: Professor J. C. Goligher, Department of Surgery, the General Infirmary at Leeds.
}

The age of distribution is remarkably similar between the sexes, $50 \%$ of the cases beginning at 20 to 39 years, $26 \%$ at 40 to $59,15 \%$ before 20 , and only $9 \%$ from 60 years onwards.

Of the 204 first-attack patients $20 \%$ presented within two months of the onset of symptoms, $60 \%$ within three months, and $90 \%$ within six months. Of the 261 relapse patients almost two-thirds presented within 10 years of the onset of symptoms.

The diagnosis in each patient was made during life on the basis of characteristic symptoms, in association with typical changes either on sigmoidoscopic or on radiological examination. Microscopical examination and culture of the stools were performed in the majority of patients, and revealed no specific infective cause for the symptoms. Several patients diagnosed at first as suffering from colitis and subsequently found to be suffering from Crohn's disease of the colon or ileum were excluded from this survey.

In the conduct of this survey all 465 personally compiled case histories were analysed, the great majority of patients having been seen and examined by sigmoidoscopy in the clinic at six- or twelve-monthly intervals since their original presentation. A barium enema examination was performed in most patients at two-yearly intervals. Further information was obtained in many cases from private medical practitioners, and from the case histories of other hospitals to which the patient had been admitted for the treatment of colitis.

All the surviving patients were traced, and all but eight were personally interviewed by one of us during the latter part of 1963 ; each of the remaining eight patients answered a detailed postal questionary.

Table I.-Composition of Series by Sex and Age at Onset of Symptoms

\begin{tabular}{c|c|c|c}
\hline Age at Onset (Years): & Male & Female & Total \\
\hline $0-9$ & 3 & 4 & 7 \\
$10-19$ & 27 & 36 & 63 \\
$20-29$ & 42 & 71 & 113 \\
$30-39$ & 51 & 67 & 18 \\
$40-49$ & 27 & 48 & 75 \\
$50-59$ & 23 & 24 & 47 \\
$60-69$ & 10 & 2 & 32 \\
$70-79$ & 7 & 1 & 9 \\
Unknown & & 275 & 465 \\
\hline Total patients & 190 & & \\
\hline
\end{tabular}

